\title{
Giant Congenital Melanocytic Nevus with Limb Hypoplasia and Lipomatosis: A Rare Association
}

\author{
Savita Arya ${ }^{1}$, Manali Jain ${ }^{2}$, Motilal Bunkar ${ }^{3}$ and Rajendra Takhar ${ }^{3^{*}}$ \\ ${ }^{1}$ Department of Dermatology, Govt Medical College, Kota, Rajasthan, India \\ ${ }^{2}$ Department of Dermatology, Pandit Madan Mohan Malviya Hospital, Delhi, India \\ ${ }^{3}$ Department of Respiratory Medicine, Govt Medical College, Kota, Rajasthan, India
}

*Corresponding author: Rajendra Takhar, Department of Respiratory Medicine, Govt Medical College, Kota, Rajasthan, India, Tel: +919784006021; E-mail: drrajtakhar@gmail.com

Rec date: September 08, 2015; Acc date: February 24, 2016; Pub date: February 27, 2016

Copyright: @ 2016 Arya S, et al. This is an open-access article distributed under the terms of the Creative Commons Attribution License, which permits unrestricted use, distribution, and reproduction in any medium, provided the original author and source are credited.

\begin{abstract}
The congenital melanocytic nevi (CMN) are very rare, hyper pigmented macular lesions formed by overgrowth of the melanocytes and melanoblasts. This exists since birth and also named as bathing trunk, coat sleeve or stocking nevi. They occur in less than $1 \%$ of the neonates in any site of the body but commonly occur over the trunk and thigh areas. The giant congenital nevus is greater than $20 \mathrm{~cm}$ in size, pigmented and often hairy. Here, we are discussing a classical case of large congenital melanocytic nevus presented over right part of torso, lower limb, lower back and buttocks, with multiple satellite lesions all over body with right lower limb hypotrophy. The diagnosis was confirmed by histopathology. Apart from the rarity of the disease, this case report highlights the rare association of CMN with hypotrophy of limb.
\end{abstract}

\section{Key words:}

Congenital melanocytic nevi; Limb hypotrophy; Histopathology

\section{Introduction}

Congenital melanocytic nevus $(\mathrm{CMN})$ is defined as a melanocytic nevus present since birth or presenting within first few months of life, is a circumscribed, light brown to black patch or plaque, covering a surface area of any size involving any site of the body. Usually, they are small in size $(\sim 90 \%)$ but the giant congenital nevus is greater than 20 $\mathrm{cm}$ in size, dark brown to black in color, with verrucous surfaces and satellite lesions which are present beyond the periphery of the main lesion [1]. The giant nevi present over the scalp and neck may be associated with various neurological disorders like; leptomeningeal melanocytosis, neurofibromatosis and epilepsy [2]. The overall incidence of malignant melanoma arising in a giant congenital nevus is estimated to be approximately $5-10 \%$ and half of all melanomas that arise in the giant congenital naevus do so by 5 years of age. Here, we are discussing a case of CMN in an eight month old female child with hypotrophy of right lower limb and without any malignant transformation and neurological involvement.

\section{Case report}

An eight month old female child presented with complaints of large, asymptomatic, black, hairy pigmented lesion over the right part of chest $\&$ abdomen, whole of pelvic girdle, right lower limb up to knee, upper part of the left thigh and lower back, buttocks up to mid-thigh with multiple satellite lesions all over the body, few of them shows hypertrichosis and lipomatous lesion (Figure 1a and 1b). Multiple pigmented satellite lesions of $4-5 \mathrm{~cm}$ size were also present over the body also. The $\mathrm{x}$-ray of pelvis showed right lower limb hypotrophy (Figure 2). No other loco motor abnormality was detected.

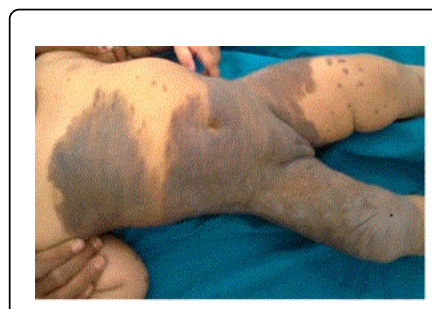

$\mathbf{A}$

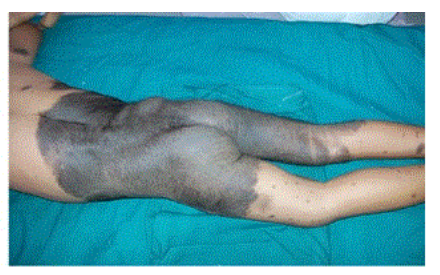

B
Figure 1: a) Hypertrichosis, lipoma b) Multiple satellite lesion.

Her systemic examinations were within normal limit including neurological system. All routine blood investigations were normal including x-ray chest and spine, electrocardiogram and computerized tomography scan of the head. The family history showed nothing abnormal as any congenital nevi or melanoma.

The biopsy from the large patch taken and histopathological revealed characteristic of congenital compound melanocytic nevus: pigmentation of basal layer, a focal collection of melanocyte in dermis, extension of naevus cells between collagen bundles singly and extension of cells around nerves, blood vessels and adnexa. No cellular atypia or malignant transformation was seen (Figure 3). Ultrasonography showing elongated lesion predominantly hypo-echoic compared to surrounding subcutaneous tissue suggestive of lipoma. Atrophy of subcutaneous tissue of right lower limb (arrow) compared to the left (arrow head) is noted (Figure $4 \mathrm{a}$ and $4 \mathrm{~b}$ ). 


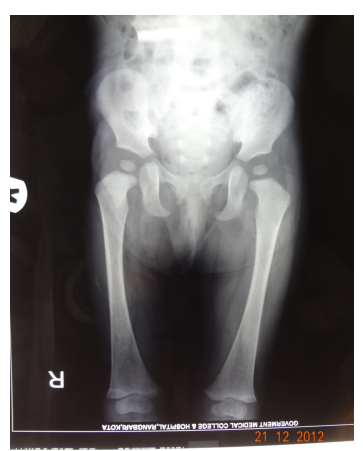

Figure 2: Right lower limb hypotrophy demonstatrated on pelvic Xray.

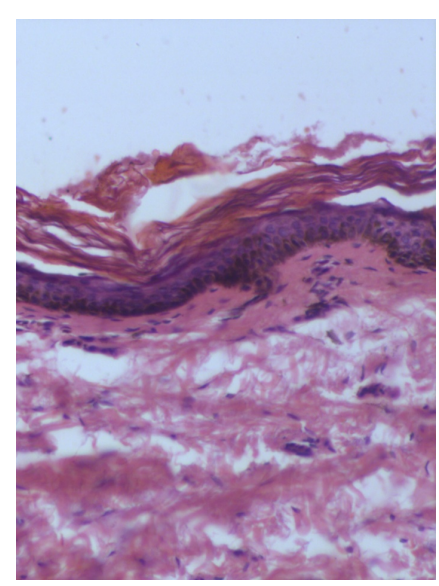

Figure 3: Histopatholgy slide demonstrating pigmentation of basal layer, focal collection of melanocyte in dermis, extension of nevus cells between collagen bundles.

\section{Discussion}

Nevus, a Latin word Knee-vus meaning "birthmark" or "mole" is a general term for a congenital mark on the skin. It was first described by Rokitansky in 1861, in a 14-year-old girl. CMN are pigmented cutaneous lesions which are formed by a combination of epidermally and dermally derived nevus cells, which occur in about $1 \%$ of the newborns. However, its exact pathogenesis is unclear, but few hypotheses explain its occurrence. According to Cramer et al., CMN are fashioned by overgrowth of the melanocytes. They are triggered by malformations of the neuroectoderm that comprised of melanocytes and occasionally neural elements, following dysregulated growth and arrest of melanocytes during migration from the neural crest to the skin [3]. According to Bauer et al, mutation (usually NRAS) results in the abnormal extensive accumulation of melanocyte cells along migration pathways during normal development [4].

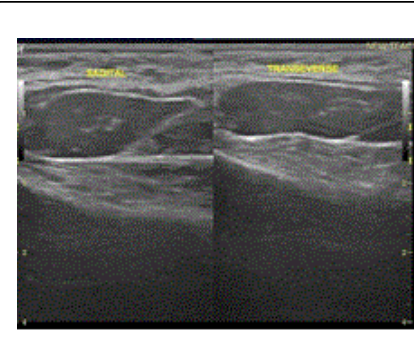

a

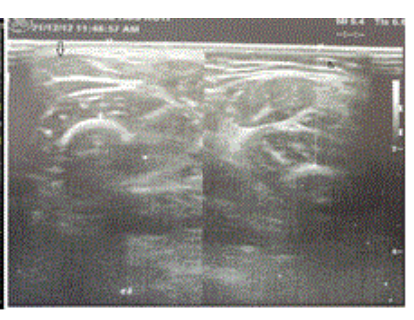

b
Figure 4: Ultrasonography showing (a) Elongated lesions predominantly hypoechoiec compared to surrounding subcutaneous tissue suggestive of lipoma and (b) Atrophy of the subcutaneous tissue of right lower limb (arrow) compared to the left (arrow head) is noted.

The CMN are classified as single or multiple (more than three lesions) according to number and large (size $>20 \mathrm{~cm}$ ), medium (1.5 to $19.9 \mathrm{~cm})$ and small $(<1.5 \mathrm{~cm})$ according to their size. Giant congenital nevi occur most commonly on the posterior trunk, but may also appear on the head or the extremities have an irregular margin often with a verrucous surface. Their color is typically dark brown to black and $95 \%$ of them have dark, coarse surface hair. Satellite lesions are often present beyond the periphery of the main lesion and may be scattered over the entire skin surface. Around the age of 10 the giant nevus becomes more elevated, verrucous, and hyperkeratotic and the surface hair thicker.

There are various abnormalities association with giant $\mathrm{CMN}$ are limb hypoplasia/hyperplasia, ear deformities and vascular angiomas [5]. Persistent limb atrophy in association with a giant congenital melanocytic nevus is very rarely described as seen in our case. CMN also associated with Dandy-Walker malformation, hemi-hypertrophy of the leg, neurofibroma and spina bifida occulta. These abnormalities occur due to defects in the neural crest, which is considered to be a common origin of melanoblasts, Schwann cells, sensory ganglia, bone, fat, muscle and blood vessels [6,7]. The Malignant potential of CMN ranging from $2-41 \%$ and depend upon the site, size of lesions and age of the patient. The lesion involving head and neck area may be associated with leptomeningeal melanocytosis producing seizures, hydrocephalus and mental changes leading to death. The surgical treatment of GCMN should be addressed at the age of 6 months. The surgical technique included is serial excision and reconstruction with skin grafting, tissue expansion, local rotation flaps and free tissue transfer. The carbon dioxide laser, Er:YAG and the Qswitched. Ruby laser has all been recently used for resurfacing and for selectively treating the deep pigmentations.

\section{Conclusion}

The association of congenital melanocytic nevus with limb hypotrophy and lipoma is a relatively rarely reported. The objective of surgical treatment is to improve the cosmetic appearance of CMN and reduce the risk of malignant transformation. Furthermore, careful long-term follow-up is essential to monitor the cosmetic outcomes and the risk of malignancy. 
Citation: Arya S, Jain M, Bunkar M, Takhar R (2016) Giant Congenital Melanocytic Nevus with Limb Hypoplasia and Lipomatosis: A Rare Association. Pigmentary Disorders 3: 238. doi:10.4172/2376-0427.1000238

Page 3 of 3

\section{References}

1. Taksande A, Vilhekar K (2014) Congenital giant pigmented nevus. J Mahatma Gandhi Inst Med Sci 19: 65-66.

2. Arons MS (2002) Management of giant congenital nevi. Plast Reconstr Surg 110: 352-353.

3. Sharma D, Sharma CM (2013) Large facial congenital melanocytic nevus: a case report. Int J Res Med Sci 1: 576-578.

4. Bauer J, Curtin JA, Pinkel D, Bastian BC (2007) Congenital melanocytic nevi frequently harbor NRAS mutations but no BRAF mutations. J Invest Dermatol 127: 179-182.
5. Gonul M, Soylu S, Gul U, Aslan E, Unal T, Ergul G, et al. (2009) Giant congenital melanocytic naevus associated with Dandy-Walker malformation, lipomatosis and hemihypertrophy of the leg. Clin Exp Dermatol 34: 106-1069.

6. Gulati R, Jain D, Mehrania K, Kuldeep CM, Mathur D (2000) Giant congenital nevomelanocytic nevus with satellite lesions, vitiligo and lipoma : a rare association. Indian J Dermatol Venereol Leprol 66: 316-317.

7. Das SK, Subudhi MM (2013) Giant congenital melanocytic nevi: a case report. J Clin Diagn Res 7: 154-155. 